\title{
Study on Optimization of Governance Structure of Private SME--An Example of WHFST System Engineering Co.
}

\author{
Xiao-Hua LIN ${ }^{1, a,{ }^{*}}$ \\ ${ }^{1}$ Business School, Wuhan Yangtze Business University, Wuhan, Hubei 430065, China \\ a2442813799@qq.com \\ ${ }^{*}$ Corresponding author
}

Keywords: Private enterprise; governance structure; incentive and restraint; checks and balances; information disclosure

\begin{abstract}
Governance structure is the cornerstone of the modern enterprise system, and equity structure is the core of the governance structure. During more than 10 years of development history, WHFST C. made timely reforms, improved corporate governance and made use of advantages of private enterprise equity structure, having established the governance structure of duties clear, reasonable division of labor, checks and balances and incentive and constraint mechanism combination of enterprise benefits, risk and remuneration and positions, which provided the reference for the reform of the governance structure system of private enterprises.
\end{abstract}

\section{Introduction}

Since the beginning of reform and opening up, with the deepening of economic restructuring, SME have developed rapidly, and they play an increasingly important role in national economic and social development. Early researches of the SME are with the help of macro-background or the general theory of corporate governance, they researches about opportunities and challenges faced by the growing SME under the structure of established the social service system (Bryson j. r. and Daniels P.W,1998), as well as government support system for SME (James Curran,2002), and literatures about industrial promotion policies for SME(Bennett R. and Robson P,2000), SME entrepreneurship and economic development (WREN C,2001), regional service policy on the promotion of SME (Armstrong h. W,2001), SME clusters (Chou Baoxin,1998), policy environment for SME (Ge Licheng,2004), etc, which have changed views of all walks of life on SME, and became a theoretical basis for every country to promote the development of SME. As the SME Board (also called GEM in some countries) launched and a number of SME developed and grew and other SME went to decline, special corporate governance issues based on SME came into people's perspective, S.Carter (2006) explored the design of mechanism of SME, r. J.Rosen(2007) studied on the competitive advantages and competitiveness of SME, Lin hanchuan (2003) built the competitiveness and evaluation system of SME. At the same time, we also should recognize that existing studies on the heterogeneity of growth of SME is not enough, and studies on governance structure of the rapid developing private enterprises in recent years lags ever further. This study, is only for individual case of private enterprises in Hubei Province, however, it could be a meaningful exploration if it is to attract a greater number of academic attention and discussion and to give rise to more SME to carry it out in practice.

Taking the chance of opening up and enlivening economy, WHFST systems engineering Co. established in Wuhan, which is noted for its "thorough fares of nine provinces" in 1999 , which is founded by the General Yang and General Wu together. It was renamed as WHFST system engineering Co., LTD (hereinafter referred to as WHFST Co.). By the end of 2011, the company had fixed assets of more than $¥ 2,000$ million and liquid assets of more than $¥ 800$ million, and it absorbs hundreds of people as their staffs. Now it comes to be a high-tech enterprise which is specialized in software research, software sales, e-Government, system integration and software 
engineering quality inspection. In recent years its annual production value is $¥ 1,000$ million or so, in 2011 it even reached $¥ 1500$ million.

WHFST Co. attaches great importance to motivation of equity in the development of the company. During the period of the equity structure adjustment(WHFST Co. called it the system reform), which was started in 2010 and still been advancing gradually, the company positively introducing high quality technology stocks and administration stocks, creating a 35\% Net assets profit margin. In the design of the corporate governance structure, by using the efficiency advantages of privatization, WHFST Co. established an incentive and constraint mechanism combined of reasonable division of labor, performance and payment, and also established the trinity disclosure mechanism containing monitoring system, regular reporting and internal risk control.

\section{Separation of equity: the logic starting point of governance structure of SME}

Equity structure is the core issue of corporate governance, it has two meanings: the first meaning is the equity concentration, namely percentage of shareholding by each shareholder, there are three types of equity concentration in the area of corporate governance practices: the first is the high concentration of equity, namely there is an absolute controlling shareholder (generally is more than $50 \%$ ) who held the vast majority of shares; the second is high dispersed of equity, namely there don't exist an absolute controlling shareholder, equity of the company scattered across a large number of shareholders; the third is the relative concentration of equity, namely there is a relative majority shareholder, but the relative majority shareholders did not have the overwhelming majority (generally is less than 50\% ) shares, but is the largest shareholders of the company. Many scholars both home and abroad did a great number of researches about the relationship between equity structure and corporate governance performance, research findings include conclusions such as equity structure and corporate governance performance are positive relationship (Levy , 1983; Grossman , 1980; Grossman \& Hart,1988;Demsetz ,1985; La Porta,1999; Blair , 1995; Cleassens, 1997; Classens \& Djankov,1999; Classens,2000; Pedersen \& Thomsen,1999; Lin \& Servaes,2003; Shleifer \& Vishny,1986; Shleifer \& Vishny,1997; Gordon\&Schmid,2000), negative relationship (Jensen\&Meckling,1976;Demsctz,1983; Burkart, andGromb\&Panunzi,1997), curve relationship(Stulz,1988; Servaes,1990; Morck,Nakamura \& Shivdasani,2000; McConnell \& Servaes,1990; Cho,1998) and not related(Vives,2001; Stigler\&Friedland,1983;Demsctz\&Lehn,1985). The second meaning of equity structure is individual characteristics of the shareholders (mainly refers to the controlling shareholders), namely nature of the controlling shareholder. Scholars both home and abroad also conducted a large number of studies on the relationship between the nature of the controlling shareholders and corporate governance performance, a small amount of research shows that corporate governance performance and State-owned stocks proportion are positive related (Chen,1998; Yu Dongzhi,2001; Zhou Yean, 1999 ; Sun , Tong \& Tong,2002 ). More researches agreed of the positive role of non-State-owned shares but not in support of efficient of State-owned shares (Shawn Xu, and Wang yan,1999; Chen, and Tiger, 2000; Dong Xiuliang, 2001; Chen Xiaoyue, and Xiaodong Xu, 2003; Zhang Lei, 2004 ). Despite the researches above are based on its different assumptions, or used different samples, or had different conclusions, it is undoubtedly that equity structure of company connotes specific equity concentration and identity of the major shareholders and it is the foundation of corporation governance. Different equity structures result in different ways and effects of power operation of company and finally led to different economic consequences.

Within the framework of the corporate governance structure of private enterprises, equity structure is concerned as the first element (Dong Fuhua, 2011). From the analysis based on equity structure, Generally the original shareholder( who are riched for establishing a business )are taking in charge of the core shareholders, so not only will they be able to full of motivation and will be eligible to establish the effective governing structure but also is good for reducing the cost of agent 
WHFST Co. grasped the opportunities of speeding up the infrastructure construction of Wuhan City, by supporting the two business module of the construction and inspection of steel structure around the market buoyant demand for construction materials and quality testing, it contributes to the company's dramatically performance and the company's rapid growth, and also cultivates few department managers who grow up together with the company. Owing to years of hardworking in the company, the management level has not only accumulated a lot of knowledge about operating but also has personal capital in savings. Under the circumstances, founders of WHFST Co.-General manager Yang and General manager $\mathrm{Wu}$ generously yield part of their equity so as to attract managers to be the shareholders of the company. WHFST Co. starts its system reform in 2000.

Thanks to the hard working style of the company, scientific management and incentive mechanism, the development and education of software grew up gradually while testing of steels and steel structures in the company maintains positive growth. In 2007, in reply of the union intention of customer, the company increased capital for the first time and added a few customers as shareholders, which had created great opportunities for the company to develop in a diversified way. The company brought up professional managers of software development and education smoothly. In 2010, the company increased its capital again, which had provided opportunities for the managers to be shareholders and laid the foundation for further sustainable development of the company.

WHFST Co. also has the keen ability to capture market opportunities. in 2011 the company was optimistic about the shipping industry and merged two companies that were almost break because of the break the chain of funds, acquiring two 5,000 tonnage of ships.

Throughout the system reform of WHFST Co., there are three features as follow: First, choose the appropriate time to complement the decentralization of equity structure step by step. WHFST Co. chose appropriate time under the premise that there were appropriate shareholders who want to in and complement the increase of capital and decentralization of equity structure step by step, but not increase capital blindly. After the dispersion of Equity, supervisors are naturally diverse, which to a certain extent, reduce the information asymmetry and stimulated the activity of individual shareholders. Second, Founder holdings never wavered on the status. In the process of mergers of ship business, WHFST Co. initially received of is shares of invited. Actually it intends to take funds from WHFST Co. to remit its pressing. WHFST Co. called up all shareholders to discuss the matter, and it turned out to be that all shareholders propose share holding and against joint-stock, because in the case of joint-stock, WHFST Co. would have no choice but to follow the strategy and business decision made by the former failing ship company and do nothing, let alone to save it.

\section{The checks and balances: the key of optimization of governance structure of private enterprises}

The original intention of the governance structure arrangements of company that stipulated in company law is to enable companies to form a system of distinct responsibilities and mutual constraints so as not only to safeguard property owner's rights and interests, but also give the operator full autonomy in management. Since 2000, WHFST Co. grasping the opportunity of system reform, gradually build the Board of shareholders, the Board of Directors, Board of supervisors, according to the principles of Co-governance of separation of powers, checks and balances and accountability, and gradually optimize mechanisms and boundary of responsibilities of governance and management, ensuring that the mode of operation and business objective will balance the needs of all stakeholders. The characteristic of private property of the owner determines explicit clients and supervision in place, and helped to prevent moral hazard and lazy behavior of operators. Owing to the reasonable governance structure, not only did WHFST Co. avoid the arbitrary decision-making risk that can be easily caused by the single-large shareholder, but also 
formed a smooth decisions transmission mechanism which contributes to the effective performance of the Board of Directors' decisions and supervision. In general, the governance structure of WHFST Co. embodies the idea of checks and balances of the right of management, and realized the unity of democracy, efficiency and scientificity in a good way. WHFST Co. is not a listed company and doesn't belong to the public, but in order to strengthen the supervision of executives performance, financial and business, the company formed the Board of supervisors include 1 external persons, 2 shareholders and 2 employees of, forming a unique and effective method of supervision.

\section{Incentive: core of governance structure of private SME}

Rational and effective incentive and restraint mechanisms just like engines that guide management level to lead the company on the fast track of sustainable development. Reasonable property right system and governance structure of WHFST Co. decided its good incentive constraints mechanism -- on one hand, through company governance structure there formed a powerful incentive on executives level, which makes executives level completed agent tasks according to the requirements of target of running the company. And to realize their self value while better implementing the target of client. On the other hand, through supervision and punishment mechanism of Board of directors and Board of supervisors and the agent contract, there formed effective constraints on agent for the purpose of preventing reverse selection of agent, and meanwhile to carry out accountability and punishment to the executives and operators level who misconduct his work.

The equity of WHFST Co. are all natural stocks, and it is among the shareholders, so its principal-agent chain is relatively simple and its information loss will be reduced, which laid the foundations for the establishment of an effective incentive and restraint mechanism. After more than 10 years of research and improvement, according to the requirements of the salary management of modern enterprise system WHFST Co. established the incentive and restraint mechanism contains the combination of benefit, risk and salary, the combination of short-term incentives and long-term incentive, the combination of explicit incentive and implicit incentive and the combination of incentive and punishment.

1. Creating "open" equity structure and providing insider incentive

Board of shareholders of WHFST Co. put forward the "open" equity structure, means that the equity structure is expanding and welcome new shareholders to join at any time. For internal executives level, company gives attractive incentive policy: after became shareholders of the company, $30 \%$ of profit implemented in all the business division have to hand to assets management Committee of company (assets management committee specifically exercise rights of acquisition, transformation and disposal of assets of the company), the rest will be distribute according to the profit distribution policy of the manager of the business sector so as to release the pressure of executives level up to the hilt.

WHFST Co. used the market competition mechanism of survival of the fittest to inspire executives' pursuit for "honorable incentive". On one hand, only the talent can be selected as executives; on the other hand, distribute positions for people in charge of various business divisions within the company according to their expertise, and try to avoid weaknesses so as to exclude the subjectivity of implementation of performance evaluation and compensation plans.

2. Scientific and reasonable monitoring and assessment mechanisms, to form effective constraints of management

WHFST Co. established accountability mechanisms for execution of the decisions of board of 
directors by the management level, strengthened the following evaluation of performance of the management, and formulated a reasonable assessment system. Meanwhile, take the evaluation results as a basis for management position change, salary and reward so as to ensure that operations of management are in line with the direction of Board's strategic. The Board of supervisors holds the management level accountable about their acts of violation of regulations and acts in damage of the related interests.

\section{The smooth flow of information: guarantee of optimization of governance structure of private SME}

To ensure the supervision in place and avoid deviation of the supervision decisions, it has become an inevitable choice for the company to establish the communication mechanism of information flow. Non-listed companies, which are different from listed public companies, don't have the obligation of information disclosure, which lead to the lack of the compulsive institutional arrangements for its transparent of information. WHFST Co. noticed this issue, so the company conducted Automation of Office, established an internal flow of information platform - weekly that make real time report about emergency issues and help investors and regulators to master the true operating performance of the company so as to standardize the daily running of the company.

In addition to establish information platforms within the company, WHFST Co. also take the initiative to disclose company operating information to the regulator or the relevant Department and deliver the intrinsic value and sustainable growth potential of the company outward to win the recognition of the outside world.

\section{Conclusions and recommendations}

Good governance structure is the foundation of sound development and sustainable growth of enterprises. Equity structure plays a fundamental role in corporate governance. The relative isolation of equity structure of WHFST Co. is very efficient in its growing period, which is a reference for the private enterprise. Privatized equity subject determines the shareholders good oversight of private equity and Board of Directors and Board of supervisors that selected directly by the shareholders avoid increasing the cost of information effectively. The single proxy chain of Board of Directors and Board of supervisors directly responsible to the shareholders ensured that decisions of board of directors close to the businesses and markets, and strengthen supervision on managers and effectively prevent managers deviating from the decision of the board of directors. Incentive and restraint mechanisms of WHFST Co. played a central role in the governance structure. According to information board of directors can make an objective assessment of the Board operator and make the implementation of incentives including promotion, salary, benefits and so on, they can also make the implementation of binding including the appointment and removal of managers and bonus plan. Timely and comprehensive information disclosure is an effective guarantee of corporate governance and the overall constraints on corporate governance. Of course, companies with different characteristics have different modes of governance and because of shareholders' personality, preference and governance fit, other private enterprises will have different governance models, finally the performance of the corporation governance function is also very different. The governance models of WHFST Co. showed in this article has important significance for private enterprises with the same shareholder characteristics and governance fit, and has the reference value for companies of significant difference in governance background and shareholder preference on how to conduct system reform. 


\section{Reference}

[1] Wu Haiyan, Ma Chaoqun, Study on optimization of equity structure and governance of Rainbow corporate, Journal of Hunan University ( Social sciences Edition ),May, 2002

[2] Li Jinsheng, and Zhang Yingming, optimization of equity structure and improvement of corporate governance structure of listed companies, economic system reform, Feb, 2006

[3] Guo Chunli, a breakthrough of optimization of the equity structure: Perfect the corporate governance structure of, Journal of zhongyangcaijingdaxue, Sep, 2002

Dong Fuhua, May, 2011 